\title{
Capturing the Diversity of Wild Malus orientalis from Georgia, Armenia, Russia, and Turkey
}

\author{
Gayle M. Volk ${ }^{1}$, Christopher M. Richards, Adam D. Henk, Ann A. Reilley, \\ and Patrick A. Reeves \\ National Center for Genetic Resources Preservation, U.S. Department of Agriculture, 1111 S. Mason \\ Street, Fort Collins, CO 80521 \\ Philip L. Forsline \\ Plant Genetic Resources Unit, U.S. Department of Agriculture, Geneva, NY 14456-0462 \\ Herb S. Aldwinckle \\ Department of Plant Pathology, Cornell University, Geneva, NY 14456-0462
}

\begin{abstract}
AdDitional Index words. apple, microsatellite, genetic diversity, core collection
AbSTRACt. Seeds from wild Malus orientalis trees were collected during explorations to Armenia (2001, 2002), Georgia (2004), Turkey (1999), and Russia (1998). Seedling orchards with between eight and 171 individuals from each collection location were established at the U.S. Department of Agriculture-Agricultural Research Service Plant Genetic Resources Unit (PGRU) in Geneva, NY. Genotypic (seven microsatellite markers) and disease resistance data were collected for the $776 \mathrm{M}$. orientalis trees. The genetic diversity of the 280 individuals from Armenia and Georgia was compared with data previously published for the $M$. orientalis individuals from Russia and Turkey. A total of 106 alleles were identified in the trees from Georgia and Armenia and the average gene diversity ranged from 0.47 to 0.85 per locus. The genetic differentiation among sampling locations was greater than that found between the two countries. Six individuals from Armenia exhibited resistance to fire blight (Erwinia amylovora), apple scab (Venturia inaequalis), and cedar apple rust (Gymnosporangium juniperi-virginianae). The allelic richness across all loci in the individuals from Armenia and Georgia was statistically the same as that across all loci in the individuals from Russia and Turkey. A core set of 27 trees was selected to capture $93 \%$ of the alleles represented by the entire PGRU collection of $776 \mathrm{M}$. orientalis trees. This core set representing all four countries was selected based on genotypic data using a modified maximization algorithm. The trees selected for the $M$. orientalis core collection will be added to the main field collection at the PGRU.
\end{abstract}

Wild Malus orientalis and Malus sieversii populations from the Middle East and Central Asia may be primary progenitor species to the domesticated apple (Malus $\times$ domestica) (Buttner, 2001; Watkins, 1995). Populations of M. sieversii in Kazakhstan include individuals that most closely resemble the dessert apples consumed today (Luby et al., 2001). During the domestication process, apples that were brought from Central Asia to Europe may have undergone some hybridization with $M$. orientalis trees found wild in regions surrounding the Black Sea (Buttner, 2001; Ercisli, 2004).

Plant explorations have targeted wild $M$. sieversii and $M$. orientalis with the goal of enhanced germplasm representation and characterization in gene banks (Luby et al., 2001). Materials in gene banks are accessible to plant breeders. However, the quantity and extent of accessions available can be overwhelming in light of the amount of extant diversity. Genes from wild

Received for publication 3 June 2009. Accepted for publication 12 Aug. 2009. This project was partially supported by the National Research Initiative of the USDA Cooperative State Research, Education, and Extension Service (grant number 2005-00751).

Any mention of trade names of commercial products in this article is solely for the purpose of providing specific information and does not imply recommendation or endorsement by the U.S. Department of Agriculture.

We thank Joseph Postman and Richard Hannan for the collection of plant materials and helpful comments on earlier drafts of this work. We also acknowledge the excellent technical assistance of Herb Gustafson in phenotyping the germplasm for disease resistance.

${ }^{1}$ Corresponding author. E-mail: Gayle.Volk@ars.usda.gov. crop relatives can most easily be incorporated into breeding programs using either marker-assisted breeding or through the use of transformation. Both of these methods are dependent on having materials that possess the traits of interest. Development and use of core collections whereby large numbers of accessions are represented by a subset of significantly fewer individuals makes germplasm characterization more feasible and provides an entry point into a more complex collection. Maximization strategies (Gouesnard et al., 2001) have been successful for the development of core collections in Arabidopsis (McKhann et al., 2004), Medicago (Ellwood et al., 2006; Ronfort et al., 2006), Cacao (Zhang et al., 2009), and Glycine (Tavaud-Pirra et al., 2009), and Zea (Franco et al., 2006).

Malus orientalis germplasm possesses traits that are of potential interest to breeding programs (Aldwinckle et al., 2002). We previously identified 20 individuals that exhibited resistance to apple scab, fire blight, and cedar apple rust from Turkey and Russia (Volk et al., 2008). In addition, Georgian wild $M$. orientalis is valued as a drought- and rodent-resistant rootstock for production of propagated trees of named fruiting cultivars (J. Postman, personal communication). Individual genotypes identified to have resistance to disease can be used both directly in breeding programs and as a starting point for allele mining in related lineages within the collection (Borejsza-Wysocka et al., 1999; Gianfranceschi et al., 1996; Norelli et al., 1998, 2003).

The Malus field collection at the U.S. Department of Agriculture (USDA)-Agricultural Research Service (ARS)National Plant Germplasm System (NPGS)-Plant Genetic 
Resources Unit (PGRU) in Geneva, NY, field collection includes $776 \mathrm{M}$. orientalis genotypes collected from Russia, Turkey, Armenia, and Georgia. Previously, we used seven microsatellite markers to determine the levels of genetic diversity and disease resistance in the individuals from Russia and Turkey (Volk et al., 2008). In this work, we compare the diversity of the more recently acquired $M$. orientalis individuals from Georgia and Armenia with that of the individuals from Russia and Turkey. Using the entire M. orientalis data set of 776 individuals, we propose a core collection of 27 individuals that captures $93 \%$ of the allelic diversity of the PGRU $M$. orientalis. We recommend the use of this core collection for future detailed phenotypic evaluations of $M$. orientalis.

\section{Materials and Methods}

Plant materials. Seeds of $M$. orientalis trees in Russia (28 accessions in 1998), Turkey (57 accessions in 1999), Armenia (seven accessions in 2001, 2002), and Georgia (nine accessions in 2004) were collected during NPGS-sponsored explorations (Table 1; Fig. 1). Accessions from Georgia and Armenia that were collected within the same year and within a $75-\mathrm{km}$ radius were assigned to locations (Fig. 1). Seeds within an accession from the Georgia and Armenia collections were sometimes collected from several trees and thus are not necessarily maternally related. Seeds were established in the greenhouse and then planted in field collections at the PGRU. Leaf tissue was collected from each individual and sent to the USDAARS-National Center for Genetic Resources Preservation in Ft. Collins, CO, and kept at $-80{ }^{\circ} \mathrm{C}$ for DNA extraction.

Disease Resistance. Potted seedling plants were inoculated with mixed conidial suspensions of North American Races 1 to 5 of $V$. inaequalis. Plants were incubated at 100\% relative humidity in a mist chamber and infection severity was evaluated (number and types of lesions) after 4 weeks' growth in the greenhouse. Seedlings scored as resistant to apple scab had no symptoms, pinpoint lesions, chlorotic lesions, or necrotic lesions. Seedlings that produced conidia and exhibited signs of sporulation were considered susceptible.

Cedar apple rust susceptibility was determined based on the presence of pycnidia on seedling tissues 8 weeks after inoculation with basidiospores of Gymnosporangium juniperivirginianae.

Greenhouse plants were inoculated with Erwinia amylovora strain Ea273. The two youngest actively growing leaves were inoculated by transverse bisection with a pair of scissors dipped in E. amylovora $\left(1 \times 10^{9} \mathrm{cfu} / \mathrm{mL}\right)$. Necrotic lesion lengths were expressed as a percentage of the current season's shoot length and plants with less than $20 \%$ of shoot length blighted were characterized as resistant.

Molecular analysis. Genomic DNA was extracted from 280 duplicate $M$. orientalis leaf tissue samples using DNeasy 96 plant kits (Qiagen, Valencia, CA) as previously described (Volk et al., 2008). Seven microsatellite regions were amplified using primers for unlinked microsatellite regions (GD12, GD15, GD96, GD100, GD142, GD147, GD162) (Hemmat et al., 2003; Hokanson et al., 1998). Cultivars Golden Delicious, Law Rome Beauty, and Cox's Orange Pippen were standard cultivar controls. Fragments were amplified as described previously (Volk et al., 2005). Replicate products were separated on denatured acrylamide sequencing gels (model 4200; LI-COR, Lincoln, NE) and manually scored using the Saga $^{\text {TM }}$ software (LI-COR). Data were considered "missing" if allele calls were not identical for the duplicate DNA samples.

Molecular data analysis. Genetic diversity was assessed for genotypes of $M$. orientalis individuals grown from seeds collected in Georgia and Armenia by calculating indices of average gene diversity and allelic richness (Goudet, 1995). Average differentiation $\left(\mathrm{F}_{\mathrm{st}}\right)$ between $M$. orientalis samples collected in Georgia and Armenia as well as between collection locations within countries was estimated using the software package GDA (Lewis and Zaykin, 2001).

A core collection for $M$. orientalis was identified using the genotypic data for all $M$. orientalis accessions collected in

Table 1. The numbers of accessions and individuals for each collection region in Armenia, Georgia, Turkey, and Russia. ${ }^{\mathrm{z}}$

\begin{tabular}{|c|c|c|c|c|c|c|c|c|}
\hline \multirow[b]{2}{*}{ Country } & \multirow[b]{2}{*}{ Location $^{\mathrm{y}}$} & \multirow[b]{2}{*}{ Year } & \multirow[b]{2}{*}{$\begin{array}{c}\text { Total } \\
\text { accessions (no.) }\end{array}$} & \multirow[b]{2}{*}{$\begin{array}{c}\text { Total } \\
\text { individuals (no.) }\end{array}$} & \multicolumn{4}{|c|}{ Resistant individuals (no.) ${ }^{\mathrm{x}}$} \\
\hline & & & & & $\begin{array}{l}\text { Apple } \\
\text { scab }\end{array}$ & Fire blight & $\begin{array}{l}\text { Cedar apple } \\
\text { rust }\end{array}$ & $\begin{array}{l}\text { Apple scab, fire blight, } \\
\text { and cedar apple rust }\end{array}$ \\
\hline Georgia & GA & 2004 & 1 & 8 & 7 & 1 & $\mathrm{~N} / \mathrm{A}$ & $\mathrm{N} / \mathrm{A}$ \\
\hline Georgia & GC & 2004 & 1 & 14 & 14 & 1 & $\mathrm{~N} / \mathrm{A}$ & N/A \\
\hline Georgia & GD & 2004 & 3 & 58 & 57 & 11 & $\mathrm{~N} / \mathrm{A}$ & N/A \\
\hline Georgia & GE & 2004 & 1 & 17 & 17 & 4 & $\mathrm{~N} / \mathrm{A}$ & N/A \\
\hline Armenia & $\mathrm{AB}$ & 2001 & 2 & 27 & 20 & $12(10)$ & $11(14)$ & 2 \\
\hline Armenia & $\mathrm{AC}$ & 2002 & 1 & 14 & 2 & $4(7)$ & $0(4)$ & 0 \\
\hline Russia & RA & 1998 & 6 & 27 & 12 & 19 & 3 & 0 \\
\hline Russia & $\mathrm{RB}$ & 1998 & 22 & 171 & 137 & $94(6)$ & $15(3)$ & 0 \\
\hline Turkey & TA & 1999 & 5 & 44 & 31 & $13(1)$ & $22(1)$ & 0 \\
\hline Turkey & TB & 1999 & 22 & 102 & 3 & $84(3)$ & $11(63)$ & 0 \\
\hline
\end{tabular}

${ }^{\mathrm{z} N u m b e r s}$ of individuals exhibiting apple scab, fire blight, and cedar apple rust resistance are provided.

${ }^{\mathrm{y}}$ Location codes per Figure 1.

${ }^{x}$ Number of individuals for which disease resistance data were not available is provided in parentheses.

$\mathrm{N} / \mathrm{A}=$ not available. 


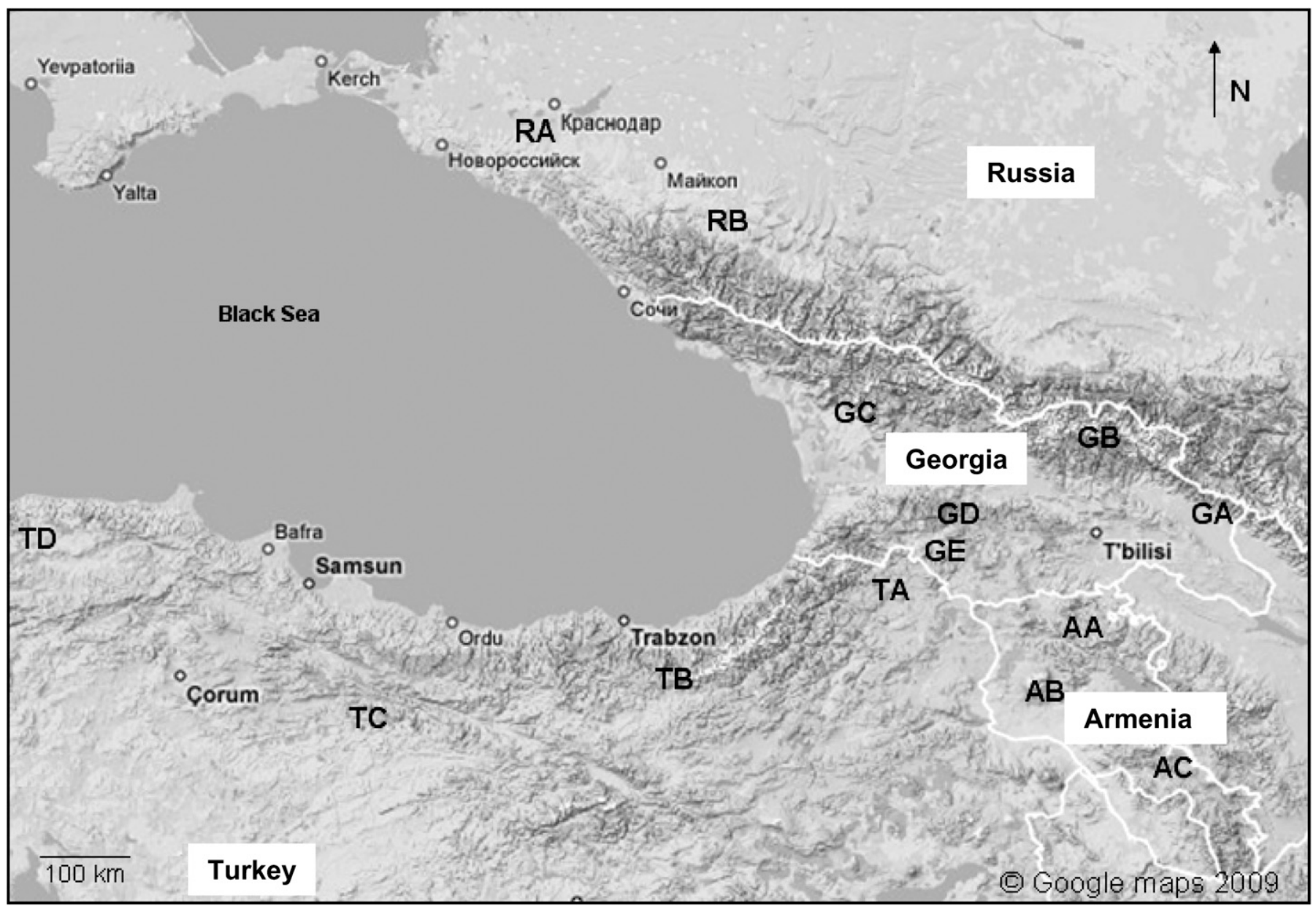

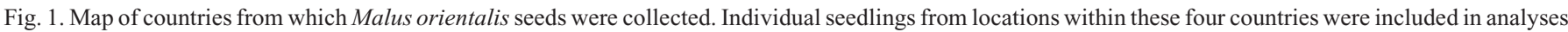
to identify a core collection.

Georgia, Armenia, Russia, and Turkey. Sample identification and microsatellite data for the Russian and Turkish samples was published previously (Volk et al., 2008). The number and selection of individuals for inclusion in the M. orientalis core set was identified using a modified MSTRAT algorithm (Gouesnard et al., 2001) that allows alleles within a diploid genotype to be considered jointly during core assembly and standardizes the contributions of individual loci to the overall diversity during core optimization (C. Richards, personal communication).

\section{Results}

Our data suggest that $M$. orientalis accessions from Georgia and Armenia contribute valuable novel germplasm to the NPGS collection. Disease resistance is a key attribute desired in apple breeding programs. A total of six individuals from Armenia were resistant to apple scab, fire blight, and cedar apple rust (Table 1). Two were introduced to the NPGS from an Armenia exploration in 2001 (GMAL 4597.f and GMAL 4598.a) and four individuals were introduced from Armenia in 2002: GMAL 4601.a, GMAL 4601.i, GMAL 4601.p, and GMAL 4602.g (Table 1). Although cedar apple rust resistance was not determined for individuals resulting from seeds collected in Georgia, 49 individuals from Georgia were resistant to both fire blight and apple scab (data not shown).
Genetic diversity, based on microsatellite analyses, was assessed for a total of 280 individuals from 16 accessions from Georgia and Armenia (Table 1). These data are complementary to that previously reported for $496 \mathrm{M}$. orientalis individuals from Russia and Turkey. A total of 106 alleles were identified within the 280 individuals sampled from Armenia and Georgia (Table 2). The number of alleles from each of the seven loci varied from two (GD15) to 22 (GD12) with five of the seven loci each yielding 16 or more alleles. The average gene diversity of the loci ranged from 0.47 (GD15) to 0.85 (GD96).

Allelic richness was calculated for $M$. orientalis individuals collected from Armenia and Georgia and classified according to location (Fig. 1; Table 3). Overall, the samples that originated in Armenia had more private alleles than those from Georgia, but allelic richness levels were comparable (Table 3). Genetic differentiation $\left(\mathrm{F}_{\mathrm{st}}\right)$ was low between the countries of Armenia and Georgia. The level of differentiation among sampling locations (nested within countries) was greater than that found between countries (Table 4).

Core COllection. All 776 M. orientalis individuals available from Georgia, Armenia, Russia, and Turkey were considered for inclusion in the M. orientalis core set. This set was selected based on the alleles identified for seven microsatellite markers, because the disease resistance data were incomplete. The methods used to select the core set were modified from 
Table 2. Descriptive statistics for each of seven microsatellite loci based on genotypic data from 280 Malus orientalis individuals that originated from seeds collected in Armenia and Georgia.

\begin{tabular}{lcccc}
\hline Marker & $\begin{array}{c}\text { Total } \\
\text { alleles (no.) }\end{array}$ & $\begin{array}{c}\text { Avg gene } \\
\text { diversity }\end{array}$ & $\begin{array}{c}\text { Minimum } \\
\text { allele size (bp) }\end{array}$ & $\begin{array}{c}\text { Maximum } \\
\text { allele size (bp) }\end{array}$ \\
\hline GD12 & 22 & 0.80 & 146 & 192 \\
GD15 & 2 & 0.47 & 142 & 145 \\
GD96 & 21 & 0.85 & 150 & 198 \\
GD100 & 8 & 0.64 & 221 & 235 \\
GD142 & 17 & 0.79 & 126 & 164 \\
GD147 & 16 & 0.72 & 117 & 257 \\
GD162 & 20 & 0.80 & 212 & \\
Total & 106 & & & \\
Avg (no./locus) & 15.1 & 0.72 & & \\
\hline
\end{tabular}

Table 3. Allelic richness was calculated for 280 Malus orientalis individuals collected from Armenia and Georgia and grouped according to collection location. ${ }^{z}$

\begin{tabular}{|c|c|c|c|c|c|c|c|c|}
\hline \multirow[b]{2}{*}{ Locus } & \multicolumn{5}{|c|}{ Georgia } & \multicolumn{3}{|c|}{ Armenia } \\
\hline & $\overline{\mathrm{GA}}$ & GB & GC & GD & GE & AA & $\mathrm{AB}$ & $\mathrm{AC}$ \\
\hline GD12 & 5.00 & 6.62 & 4.33 & 6.55 & 5.61 & 7.05 & 6.99 & 4.23 \\
\hline GD15 & 2.00 & 1.99 & 2.00 & 2.00 & 2.00 & 2.00 & 2.00 & 2.00 \\
\hline GD96 & 7.60 & 7.30 & 4.49 & 6.45 & 6.53 & 7.53 & 7.51 & 4.73 \\
\hline GD100 & 2.00 & 4.45 & 3.35 & 4.69 & 5.30 & 5.08 & 4.60 & 1.86 \\
\hline GD142 & 5.24 & 5.87 & 2.64 & 7.14 & 6.33 & 7.01 & 6.00 & 4.72 \\
\hline GD147 & 3.49 & 6.07 & 4.79 & 5.57 & 5.64 & 5.80 & 4.87 & 2.68 \\
\hline GD162 & 3.00 & 5.94 & 3.96 & 6.66 & 6.19 & 6.25 & 7.27 & 4.60 \\
\hline Mean/location & 4.05 & 5.46 & 3.65 & 5.58 & 5.37 & 5.82 & 5.60 & 3.54 \\
\hline Private alleles & 2 & 1 & 0 & 1 & 1 & 6 & 3 & 2 \\
\hline $\mathrm{N}$ & 9 & 62 & 14 & 58 & 17 & 68 & 39 & 14 \\
\hline
\end{tabular}

${ }^{\mathrm{z}}$ Location codes per Figure 1.

Table 4. Levels of Malus orientalis genetic differentiation as estimated by average differentiation ( $\mathrm{F}_{\mathrm{st}}$; with confidence intervals) calculated between Armenia and Georgia (country) and within Armenia (three locations) and Georgia (five locations).

\begin{tabular}{llc}
\hline Source & $\mathrm{F}_{\mathrm{st}}$ & $\mathrm{F}_{\text {st }}$ confidence interval \\
\hline Country & 0.005 & $-0.02-0.03$ \\
Locations (country) & 0.09 & $0.06-0.13$ \\
\hline
\end{tabular}

methods used for previous $M$. sieversii core set determinations (Richards et al., 2009; Volk et al., 2005).

The proposed $M$. orientalis core set of 27 trees includes individuals from each of the four countries (Table 5). Individuals selected based on genotypic data obtained for the set of seven microsatellite markers represent 10 of the 14 collection locations. Two individuals in the core collection are resistant to apple scab, fire blight, and cedar apple rust. Four additional individuals in the core collection are resistant to both apple scab and fire blight (Table 5).

The 27 individuals capture 123, or $93 \%$, of the total 132 alleles in the entire $M$. orientalis data set. Allele frequencies were plotted to compare representation in the core versus the entire M. orientalis datasets (Fig. 2). The frequency relationship was linear with a slope of 0.94 and an $r^{2}$ of 0.84 , suggesting that the modified core selection process was representative.

\section{Discussion}

Malus orientalis is likely a progenitor species of domesticated apples that has yet to be actively included in breeding programs. Candidate genes from Malus floribunda and $M$. sieversii that offer apple scab resistance have been identified (Boudichevskaia et al., 2009; Bus et al., 2005; Szankowski et al., 2009). M. orientalis individuals exhibiting apple scab resistance may offer novel candidate genes that could be of use to breeding programs, particularly as major resistance genes are overcome by the fungus (Soufflet-Freslon et al., 2008). The 20 diseaseresistant individuals previously identified from Russia and Turkey (Volk et al., 2008) and the six disease-resistant Armenian individuals identified here may be of particular interest to breeding programs because they offer resistance to apple scab, fire blight as well as cedar apple rust. The proposed core collection includes two individuals with resistance to all three diseases.

The 280 individuals from Armenia and Georgia complement the diversity described for the 496 NPGS Turkish and Russian M. orientalis trees. The 106 total alleles identified from Armenia and Georgia was similar in number to the 126 alleles identified from Russia and Turkey (Volk et al., 2008). When private alleles were identified for the entire $M$. orientalis collection, two alleles were unique to Armenia, one allele was unique to Georgia, and three and 10 alleles were unique to Russia and Turkey, respectively. In the combined $M$. orientalis data set, the allelic richness across all loci in the individuals from Armenia and Georgia (15.07) was statistically the same as that across all loci in the individuals from Russia and Turkey (17.13). Allelic richness was selected as the diversity measurement used to compare among locations to account for the differences between sample sizes. Genetic differentiation was higher among locations within Armenia and Georgia (0.09) relative to those among locations in Turkey and Russia (0.046). Genetic differentiation between the combined groups of individuals from Georgia-Armenia and TurkeyRussia was small but significant $\left(\mathrm{F}_{\mathrm{st}} 0.021\right.$; bootstrapped $95 \%$ confidence interval, 0.014 to 0.031$)$. For the Georgian and Armenian samples, the original seeds were not separated by mother; therefore, sampling was not performed in a manner such that estimates about family structure could be made.

Three core collections with a total number of 112 individuals have previously been proposed to represent the diversity of 949 M. sieversii accessions from Kazakhstan (Richards et al., 2009; Volk et al., 2005). These core collections were identified based on both phenotypic and genotypic data using the original MSTRAT algorithm (Gouesnard et al., 2001). Based on our findings, this algorithm likely overestimated the number of individuals needed to capture diversity because alleles at codominant loci were not considered jointly. The modified core assembly algorithm, which treats loci equally and codominant data correctly, resulted in a core for $M$. orientalis that was 


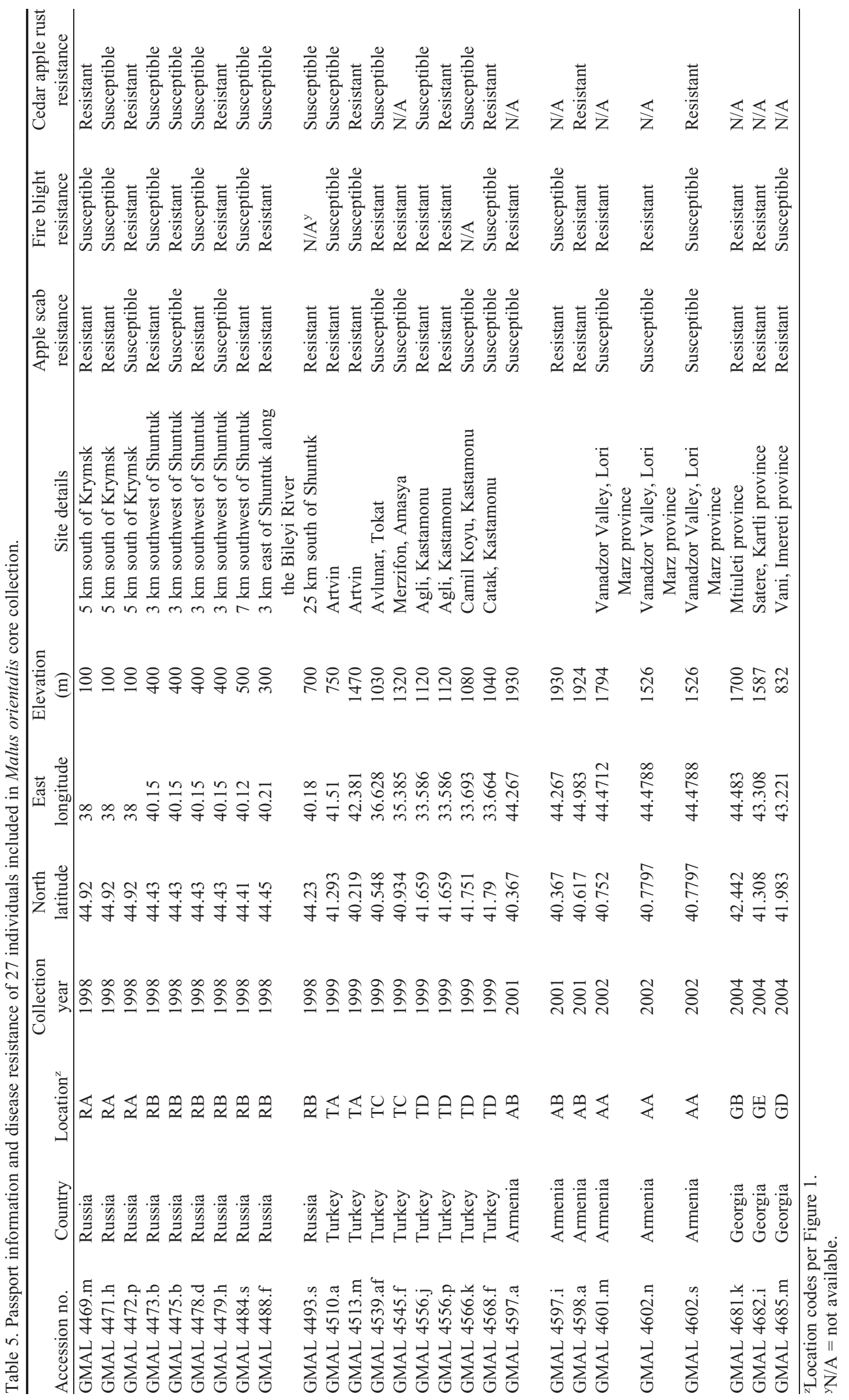




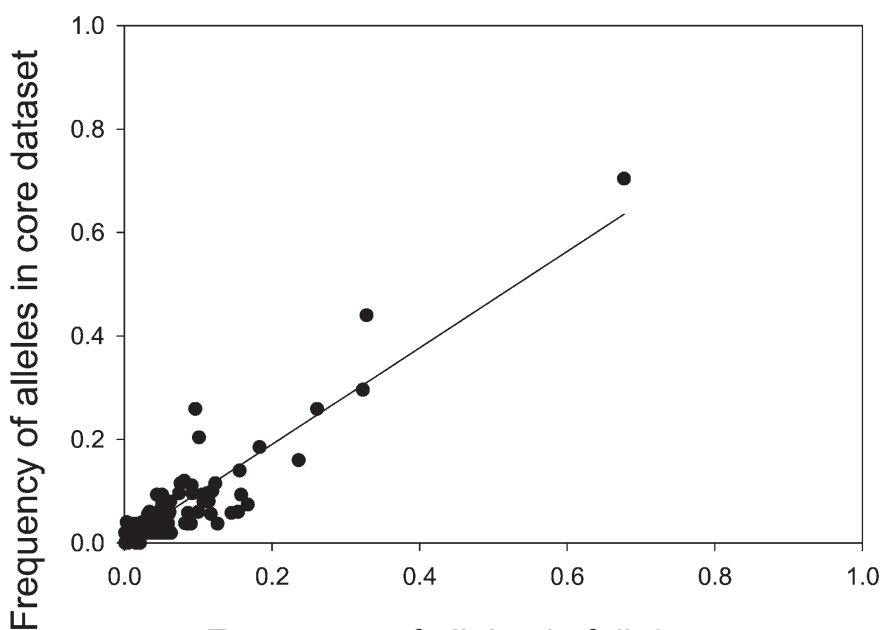

Frequency of alleles in full dataset

Fig. 2. Relationship between allelic frequency in the proposed Malus orientalis core collection of 27 individuals and the entire 776 National Plant Germplasm System-Plant Genetic Resources Unit (NPGS-PGRU) M. orientalis collection of individuals in the field.

substantially smaller than the core produced using the original MSTRAT algorithm (C. Richards, personal communication).

We have selected $27 \mathrm{M}$. orientalis individuals to represent the diversity of $776 \mathrm{M}$. orientalis individuals originating from Russia, Turkey, Armenia, and Georgia. The individuals were selected based on genotypic data because comprehensive phenotypic data were not available. We have shown that the allelic frequencies in the core set are representative of that of the $M$. orientalis trees in the PGRU collection. Narrowing the large population down to a smaller representative sample makes the $M$. orientalis collection more accessible to the breeding and research communities. Despite limited descriptive information, a conservation genetic approach that uses estimates of differentiation and a maximization strategy can produce core sets with a minimum amount of redundancy. Development of core sets can be justified when their use can be seen as an efficient entry point in the larger diversity of the collection.

Phenotypic data can be more easily collected from the core set of individuals and that data will be made publicly available on the GRIN database (USDA, 2009). The core set of individuals will also be repropagated and added to the main Malus field collection in Geneva, NY. Additional individuals that are not part of this core may also be maintained after further evaluation. Dormant buds from these individuals will be cryopreserved for long-term preservation (Forsline et al., 1998; Towill et al., 2004).

\section{Literature Cited}

Aldwinckle, H.S., H.L. Gustafson, P.L. Forsline, and M.V. Bhaskara Reddy. 2002. Fire blight resistance of Malus species from Sichuan (China), Russian Caucasus, Turkey, and Germany. Acta Hort. 590:369-372.

Borejsza-Wysocka, E.E., J.L. Norelli, H.S. Aldwinckle, and K. Ko. 1999. Transformation of authentic M.26 apple rootstock for enhanced resistance to fire blight. Acta Hort. 489:259-266.

Boudichevskaia, A., H. Flachowsky, and F. Dunemann. 2009. Identification and molecular analysis of candidate genes homologous to HcrVf genes for scab resistance in apple. Plant Breed. 128:84-91.
Bus, V.G.M., F.N.D. Laurens, W.E. van de Weg, R.L. Rusholme, E.H.A. Rikkerink, S.E. Gardiner, H.C.M. Bassett, L.P. Kodde, and K.M. Plummer. 2005. The Vh8 locus of a new gene-for-gene interaction between Venturia inaequalis and the wild apple Malus sieversii is closely linked to the Vh2 locus in Malus pumila R127407A. New Phytol. 166:1035-1049.

Buttner, R. 2001. Malus, p. 471-482. In: P. Hanelt (ed.). Mansfelds encyclopedia of agricultural and horticultural crops. Springer, New York, NY.

Ellwood, S.R., N.K. D'Souza, L.G. Kamphuis, T.I. Burgess, R.M. Nair, and R.P. Oliver. 2006. SSR analysis of the Medicago truncatula SARDI core collection reveals substantial diversity and unusual genotype dispersal throughout the Mediterranean basin. Theor. Appl. Genet. 112:977-983.

Ercisli, S. 2004. A short review of the fruit germplasm resources of Turkey. Genet. Resources Crop Evol. 51:419-435.

Forsline, P.L., L.E. Towill, J.W. Waddell, C. Stushnoff, W.F. Lamboy, and J.R. McFerson. 1998. Recovery and longevity of cryopreserved dormant apple buds. J. Amer. Soc. Hort. Sci. 123:365-370.

Franco, J., J. Crossa, M.L. Warburton, and S. Taba. 2006. Sampling strategies for conserving maize diversity when forming core subsets using genetic markers. Crop Sci. 46:854-864.

Gianfranceschi, L., B. Koller, N. Seglias, M. Kellerals, and C. Gessler. 1996. Molecular selection in apple for resistance to scab caused by Venturia inaequalis. Theor. Appl. Genet. 93:199-204.

Goudet, J. 1995. FSTAT, a program for IBM PC compatibles to calculate Weir and Cockerham's (1984) estimators of F-statistics. J. Hered. 86:485-486.

Gouesnard, B., T.M. Bataillon, G. Decous, C. Rozale, D.J. Schoen, and J.L. David. 2001. MSTRAT: An algorithm for building germplasm core collections by maximizing allelic or phenotypic richness. J. Hered. 92:93-94.

Hemmat, M., N.F. Weeden, and S.K. Brown. 2003. Mapping and evaluation of Malus $\times$ domestica microsatellites in apple and pear. J. Amer. Soc. Hort. Sci. 128:515-520.

Hokanson, S.C., A.K. Szewc-McFadden, W.F. Lamboy, and J.R. McFerson. 1998. Microsatellite (SSR) markers reveal genetic identities, genetic diversity and relationships in a Malus $\times$ domestica Borkh. core collection. Theor. Appl. Genet. 97:671683.

Lewis, P.O. and D. Zaykin. 2001. GDA user's manual. 27 July 2004. $<\mathrm{http}$ //lewis.eeb.uconn.edu/lewishome $>$.

Luby, J., P. Forsline, H. Aldwinckle, V. Bus, and M. Giebel. 2001. Silk road apples-Collection, evaluation, and utilization of Malus sieversii from central Asia. HortScience 36:225-231.

McKhann, H.I., C. Camilleri, A. Bérard, T. Bataillon, J.L. David, X. Reboud, V. Le Corre, C. Caloustian, I.G. Gut, and D. Brunel. 2004. Nested core collections maximizing genetic diversity in Arabidopsis thaliana. Plant J. 38:193-202.

Norelli, J.L., H.T. Holleran, W.C. Johnson, T.L. Robinson, and H.S. Aldwinckle. 2003. Resistance of Geneva and other apple rootstocks to Erwinia amylovora. Plant Dis. 87:26-32.

Norelli, J.L., J.Z. Mills, L.A. Jensen, M.T. Momol, and H.S. Aldwinckle. 1998. Genetic engineering of apple for increased resistance to fire blight. Acta Hort. 484:541-546.

Richards, C.M., G.M. Volk, P.A. Reeves, A.A. Reilley, A.D. Henk, P.L. Forsline, and H.S. Aldwinckle. 2009. Selection of stratified core sets representing wild apple (Malus sieversii). J. Amer. Soc. Hort. Sci. 134:228-235.

Ronfort, J., T. Bataillon, S. Santoni, M. Delalande, J.L. David, and J.-M. Prosperi. 2006. Microsatellite diversity and broad scale geographic structure in a model legume: Building a set of nested core collection for studying naturally occurring variation in Medicago truncatula. BMC Plant Biol. 6:28.

Soufflet-Freslon, V., L. Gianfranceschi, A. Patocchi, and C.-E. Durel. 2008. Inheritance studies of apple scab resistance and identification of Rvi14, a new major gene that acts together with other broadspectrum QTL. Genome 51:657-667. 
Szankowski, I., S. Waidmann, J. Degenhardt, A. Patocchi, R. Paris, E. Silfverberg-Dilworth, G. Broggini, and C. Gessler. 2009. Highly scab-resistant transgenic apple lines achieved by introgression of HcrVf2 controlled by different native promoter lengths. Tree Genet. Genomes 5:349-358.

Tavaud-Pirra, M., P. Sartre, R. Nelson, S. Santoni, N. Texier, and P. Roumet. 2009. Genetic diversity in a soybean collection. Crop Sci. 49:895-902.

Towill, L.E., P.L. Forsline, C. Walters, J.W. Waddell, and J. Laufmann. 2004. Cryopreservation of Malus germplasm using a winter vegetative bud method: Results from 1915 accessions. Cryo Letters 25:323-334.

U.S. Department of Agriculture. 2009. National genetic resources program. Germplasm resources information network (GRIN). 14 July 2009. <http://www.ars-grin.gov/cgi-bin/npgs/html/>.
Volk, G.M., C.M. Richards, A.A. Reilley, A.D. Henk, P.L. Forsline, and H.S. Aldwinckle. 2005. Ex situ conservation of vegetativelypropagated species: Development of a seed-based core collection for Malus sieversii. J. Amer. Soc. Hort. Sci. 130:203-210.

Volk, G.M., C.M. Richards, A.A. Reilley, A.D. Henk, P.A. Reeves, P.L. Forsline, and H.S. Aldwinckle. 2008. Genetic diversity and disease resistance of wild Malus orientalis from Turkey and Southern Russia. J. Amer. Soc. Hort. Sci. 133:383-389.

Watkins, R. 1995. Apple and pear, p. 418-422. In: J. Smartt and N.W. Simmonds (eds.). Evolution of crop plants. Wiley, New York, NY

Zhang, D., S. Mischke, E.S. Johnson, W. Phillips-Mora, and L. Meinhardt. 2009. Molecular characterization of an international cacao collection using microsatellite markers. Tree Genet. Genomes 5:1-10. 